\title{
Fixed point theorems for weak $C$-contractions in partially ordered 2-metric spaces
}

\author{
Nguyen Van Dung ${ }^{1 *}$ and Vo Thi Le Hang ${ }^{2}$
}

\author{
*Correspondence: \\ nvdung@dthu.edu.vn; \\ nguyendungtc@yahoo.com \\ 'Department of Mathematics, Dong \\ Thap University, Dong Thap, Dong \\ Thap, Vietnam \\ Full list of author information is \\ available at the end of the article
}

\begin{abstract}
The aim of this paper is to state some fixed point results for weak C-contractions in a partially ordered 2-metric space. Examples are given to illustrate the results.
\end{abstract}

\section{Introduction and preliminaries}

Chatterjea in [1] introduced the notion of a $C$-contraction.

Definition 1.1 [1] Let $(X, d)$ be a metric space and $T: X \rightarrow X$ be a map. Then $T$ is called a $C$-contraction if there exists $\alpha \in\left(0, \frac{1}{2}\right)$ such that for all $x, y \in X, d(T x, T y) \leq \alpha[d(x, T y)+$ $d(y, T x)]$.

This notion was generalized to a weak $C$-contraction by Choudhury in [2].

Definition 1.2 ([2], Definition 1.3) Let $(X, d)$ be a metric space and $T: X \rightarrow X$ be a map. Then $T$ is called a weak $C$-contraction if there exists $\psi:[0, \infty)^{2} \rightarrow[0, \infty)$ which is continuous, and $\psi(s, t)=0$ if and only if $s=t=0$ such that

$$
d(T x, T y) \leq \frac{1}{2}[d(x, T y)+d(y, T x)]-\psi(d(x, T y), d(y, T x))
$$

for all $x, y \in X$.

In [2], Choudhury proved that if $X$ is a complete metric space, then every weak $C$-contraction has a unique fixed point; see [2, Theorem 2.1]. This result was generalized to a complete, partially ordered metric space in [3]; see [3, Theorems 2.1, 2.3 and 3.1].

There were some generalizations of a metric such as a 2-metric, a $D$-metric, a $G$-metric, a cone metric, and a complex-valued metric. The notion of a 2-metric has been introduced by Gähler in [4]. Note that a 2-metric is not a continuous function of its variables, whereas an ordinary metric is. This led Dhage to introduce the notion of a $D$-metric in [5]. But in [6] Mustafa and Sims showed that most of topological properties of $D$-metric were not correct. In [7] Mustafa and Sims introduced the notion of a G-metric to overcome flaws of a $D$-metric. After that, many fixed point theorems on $G$-metric spaces have been stated. However, it was shown in [8] and [9] that in several situations fixed point results in $G$-metric spaces can be in fact deduced from fixed point theorems in metric or quasimetric spaces.

@ 2013 Dung and Le Hang; licensee Springer. This is an Open Access article distributed under the terms of the Creative Commons Attribution License (http://creativecommons.org/licenses/by/2.0), which permits unrestricted use, distribution, and reproduction in any medium, provided the original work is properly cited. 
In [10] Huang and Zhang defined the notion of a cone metric. After that, many authors extended some fixed point theorems on metric spaces to cone metric spaces. However, it was shown later by various authors that in several cases the fixed point results in cone metric spaces can be obtained by reducing them to their standard metric counterparts; for example, see [11-14]. In [15] Azam, Fisher and Khan have introduced the notion of a complex-valued metric and some fixed point theorems have been stated. But in [16] Sastry, Naidu and Bekeshie showed that some fixed point theorems recently generalized to complex-valued metric spaces are consequences of their counterparts in the setting of metric spaces and hence are redundant.

Note that in the above generalizations, only a 2-metric space has not been known to be topologically equivalent to an ordinary metric. Then there was no easy relationship between results obtained in 2-metric spaces and metric spaces. In particular, the fixed point theorems on 2-metric spaces and metric spaces may be unrelated easily. For the fixed point theorems on 2-metric spaces, the readers may refer to [17-26].

The aim of this paper is to state some fixed point results for weak $C$-contractions in a partially ordered 2-metric space. Examples are given to illustrate the results.

First we recall some notions and lemmas which will be useful in what follows.

Definition 1.3 [4] Let $X$ be a non-empty set and let $d: X \times X \times X \rightarrow \mathbb{R}$ be a map satisfying the following conditions:

1. For every pair of distinct points $x, y \in X$, there exists a point $z \in X$ such that $d(x, y, z) \neq 0$.

2. If at least two of three points $x, y, z$ are the same, then $d(x, y, z)=0$.

3. The symmetry: $d(x, y, z)=d(x, z, y)=d(y, x, z)=d(y, z, x)=d(z, x, y)=d(z, y, x)$ for all $x, y, z \in X$.

4. The rectangle inequality: $d(x, y, z) \leq d(x, y, t)+d(y, z, t)+d(z, x, t)$ for all $x, y, z, t \in X$. Then $d$ is called a 2-metric on $X$ and $(X, d)$ is called a 2-metric space which will be sometimes denoted by $X$ if there is no confusion. Every member $x \in X$ is called a point in $X$.

Definition 1.4 [4] Let $(X, d)$ be a 2-metric space and $a, b \in X, r \geq 0$. The set

$$
B(a, b, r)=\{x \in X: d(a, b, x)<r\}
$$

is called a 2-ball centered at $a$ and $b$ with radius $r$. The topology generated by the collection of all 2-balls as a subbasis is called a 2-metric topology on $X$.

Definition 1.5 [22] Let $\left\{x_{n}\right\}$ be a sequence in a 2-metric space $(X, d)$.

1. $\left\{x_{n}\right\}$ is said to be convergent to $x$ in $(X, d)$, written $\lim _{n \rightarrow \infty} x_{n}=x$, if for all $a \in X$, $\lim _{n \rightarrow \infty} d\left(x_{n}, x, a\right)=0$.

2. $\left\{x_{n}\right\}$ is said to be Cauchy in $X$ if for all $a \in X, \lim _{n, m \rightarrow \infty} d\left(x_{n}, x_{m}, a\right)=0$, that is, for each $\varepsilon>0$, there exists $n_{0}$ such that $d\left(x_{n}, x_{m}, a\right)<\varepsilon$ for all $n, m \geq n_{0}$.

3. $(X, d)$ is said to be complete if every Cauchy sequence is a convergent sequence.

Definition 1.6 ([24], Definition 8) A 2-metric space $(X, d)$ is said to be compact if every sequence in $X$ has a convergent subsequence.

Lemma 1.7 ([24], Lemma 3) Every 2-metric space is a $T_{1}$-space. 
Lemma 1.8 ([24], Lemma 4) $\lim _{n \rightarrow \infty} x_{n}=x$ in a 2-metric space $(X, d)$ if and only if $\lim _{n \rightarrow \infty} x_{n}=x$ in the 2-metric topological space $X$.

Lemma 1.9 ([24], Lemma 5) If $T: X \rightarrow Y$ is a continuous map from a 2-metric space $X$ to a 2-metric space $Y$, then $\lim _{n \rightarrow \infty} x_{n}=x$ in $X$ implies $\lim _{n \rightarrow \infty} T x_{n}=T x$ in $Y$.

\section{Remark 1.10}

1. It is straightforward from Definition 1.3 that every 2-metric is non-negative and every 2-metric space contains at least three distinct points.

2. A 2-metric $d(x, y, z)$ is sequentially continuous in one argument. Moreover, if a 2 -metric $d(x, y, z)$ is sequentially continuous in two arguments, then it is sequentially continuous in all three arguments, see [27, p.975].

3. A convergent sequence in a 2-metric space need not be a Cauchy sequence, see [27, Remark 01 and Example 01].

4. In a 2-metric space $(X, d)$, every convergent sequence is a Cauchy sequence if $d$ is continuous, see [27, Remark 02].

5. There exists a 2-metric space $(X, d)$ such that every convergent sequence is a Cauchy sequence but $d$ is not continuous, see [27, Remark 02 and Example 02].

\section{Main results}

First, we introduce the notion of a weak $C$-contraction on a partially ordered 2-metric space.

Definition 2.1 Let $(X, \preceq, d)$ be a partially ordered 2-metric space and $T: X \rightarrow X$ be a map. Then $T$ is called a weak $C$-contraction if there exists $\psi:[0, \infty)^{2} \rightarrow[0, \infty)$ which is continuous, and $\psi(s, t)=0$ if and only if $s=t=0$ such that

$$
d(T x, T y, a) \leq \frac{1}{2}[d(x, T y, a)+d(y, T x, a)]-\psi(d(x, T y, a), d(y, T x, a))
$$

for all $x, y, a \in X$ and $x \preceq y$ or $y \preceq x$.

The following example gives some examples of $\psi$ in Definition 2.1. Note that in [2, Example 2.1], Choudhury considered the function $\psi(a, b)=\frac{1}{2} \min \{a, b\}$ for all $a, b \in[0, \infty)$. Unfortunately, for this function, we have $\psi(0,1)=0$, which is a contradiction to the condition that $\psi(s, t)=0$ if and only if $s=t=0$ in [2, Definition 1.3], also in Definition 2.1.

\section{Example 2.2}

1. $\psi(a, b)=\frac{a+b}{2}$ for all $a, b \in[0, \infty)$.

2. $\psi(a, b)=\frac{\max \{a, b\}}{4}$ for all $a, b \in[0, \infty)$.

The first result is a sufficient condition for the existence of a fixed point of a weak $C$-contraction on a 2-metric space. For the preceding one in metric spaces, see [3, Theorem 2.1].

Theorem 2.3 Let $(X, \preceq, d)$ be a complete, partially ordered 2-metric space and $T: X \rightarrow X$ be a weak $C$-contraction such that:

1. $T$ is continuous and non-decreasing. 
2. There exists $x_{0} \in X$ with $x_{0} \preceq T x_{0}$.

Then $T$ has a fixed point.

Proof If $x_{0}=T x_{0}$, then the proof is finished. Suppose now that $x_{0} \prec T x_{0}$. Since $T$ is a nondecreasing map, we have $x_{0} \prec T x_{0} \preceq T^{2} x_{0} \preceq \cdots \preceq T^{n} x_{0} \preceq \cdots$. Put $x_{n+1}=T x_{n}$. Then, for all $n \geq 1$, from (2.1) and noting that $x_{n-1}$ and $x_{n}$ are comparable, we get

$$
\begin{aligned}
d\left(x_{n+1}, x_{n}, a\right) & =d\left(T x_{n}, T x_{n-1}, a\right) \\
& \leq \frac{1}{2}\left[d\left(x_{n}, T x_{n-1}, a\right)+d\left(x_{n-1}, T x_{n}, a\right)\right]-\psi\left(d\left(x_{n}, T x_{n-1}, a\right), d\left(x_{n-1}, T x_{n}, a\right)\right) \\
& =\frac{1}{2}\left[d\left(x_{n}, x_{n}, a\right)+d\left(x_{n-1}, x_{n+1}, a\right)\right]-\psi\left(d\left(x_{n}, x_{n}, a\right), d\left(x_{n-1}, x_{n+1}, a\right)\right) \\
& =\frac{1}{2} d\left(x_{n-1}, x_{n+1}, a\right)-\psi\left(0, d\left(x_{n-1}, x_{n+1}, a\right)\right) \\
& \leq \frac{1}{2} d\left(x_{n-1}, x_{n+1}, a\right)
\end{aligned}
$$

for all $a \in X$. By choosing $a=x_{n-1}$ in (2.2), we obtain $d\left(x_{n+1}, x_{n}, x_{n-1}\right) \leq 0$, that is,

$$
d\left(x_{n+1}, x_{n}, x_{n-1}\right)=0 .
$$

It follows from (2.2) and (2.3) that

$$
\begin{aligned}
d\left(x_{n+1}, x_{n}, a\right) & \leq \frac{1}{2} d\left(x_{n-1}, x_{n+1}, a\right) \\
& \leq \frac{1}{2}\left[d\left(x_{n-1}, x_{n}, a\right)+d\left(x_{n}, x_{n+1}, a\right)+d\left(x_{n-1}, x_{n}, x_{n+1}\right)\right] \\
& =\frac{1}{2}\left[d\left(x_{n-1}, x_{n}, a\right)+d\left(x_{n}, x_{n+1}, a\right)\right] .
\end{aligned}
$$

It implies that

$$
d\left(x_{n}, x_{n+1}, a\right) \leq d\left(x_{n-1}, x_{n}, a\right) .
$$

Thus $\left\{d\left(x_{n}, x_{n+1}, a\right)\right\}$ is a decreasing sequence of non-negative real numbers and hence it is convergent. Let

$$
\lim _{n \rightarrow \infty} d\left(x_{n}, x_{n+1}, a\right)=r
$$

Taking the limit as $n \rightarrow \infty$ in (2.4) and using (2.6), we get

$$
r \leq \lim _{n \rightarrow \infty} \frac{1}{2} d\left(x_{n-1}, x_{n+1}, a\right) \leq \frac{1}{2}(r+r)=r
$$

That is,

$$
\lim _{n \rightarrow \infty} d\left(x_{n-1}, x_{n+1}, a\right)=2 r
$$


Taking the limit as $n \rightarrow \infty$ in (2.2) and using (2.6), (2.7), we get $r \leq \frac{1}{2} 2 r-\psi(0,2 r) \leq$ $\frac{1}{2} 2 r=r$. It implies that $\psi(0,2 r)=0$, that is, $r=0$. Then (2.6) becomes

$$
\lim _{n \rightarrow \infty} d\left(x_{n+1}, x_{n}, a\right)=0 .
$$

From (2.5), we have if $d\left(x_{n-1}, x_{n}, a\right)=0$, then $d\left(x_{n}, x_{n+1}, a\right)=0$. Since $d\left(x_{0}, x_{1}, x_{0}\right)=0$, we have $d\left(x_{n}, x_{n+1}, x_{0}\right)=0$ for all $n \in \mathbb{N}$. Since $d\left(x_{m-1}, x_{m}, x_{m}\right)=0$, we have

$$
d\left(x_{n}, x_{n+1}, x_{m}\right)=0
$$

for all $n \geq m-1$. For $0 \leq n<m-1$, noting that $m-1 \geq n+1$, from (2.9) we have

$$
d\left(x_{m-1}, x_{m}, x_{n+1}\right)=d\left(x_{m-1}, x_{m}, x_{n}\right)=0 .
$$

It implies that

$$
\begin{aligned}
d\left(x_{n}, x_{n+1}, x_{m}\right) & \leq d\left(x_{n}, x_{n+1}, x_{m-1}\right)+d\left(x_{n+1}, x_{m}, x_{m-1}\right)+d\left(x_{m}, x_{n}, x_{m-1}\right) \\
& =d\left(x_{n}, x_{n+1}, x_{m-1}\right) .
\end{aligned}
$$

Since $d\left(x_{n}, x_{n+1}, x_{n+1}\right)=0$, from (2.10) we have

$$
d\left(x_{n}, x_{n+1}, x_{m}\right)=0
$$

for all $0 \leq n<m-1$. From (2.9) and (2.11), we have $d\left(x_{n}, x_{n+1}, x_{m}\right)=0$ for all $n, m \in \mathbb{N}$.

Now, for all $i, j, k \in \mathbb{N}$ with $i<j$, we have $d\left(x_{j-1}, x_{j}, x_{i}\right)=d\left(x_{j-1}, x_{j}, x_{k}\right)=0$. Therefore,

$$
\begin{aligned}
d\left(x_{i}, x_{j}, x_{k}\right) & \leq d\left(x_{i}, x_{j}, x_{j-1}\right)+d\left(x_{j}, x_{k}, x_{j-1}\right)+d\left(x_{k}, x_{i}, x_{j-1}\right) \\
& \leq d\left(x_{i}, x_{j-1}, x_{k}\right) \\
& \leq \cdots \\
& \leq d\left(x_{i}, x_{i}, x_{k}\right) \\
& =0 .
\end{aligned}
$$

This proves that for all $i, j, k \in \mathbb{N}$

$$
d\left(x_{i}, x_{j}, x_{k}\right)=0 .
$$

In what follows, we will prove that $\left\{x_{n}\right\}$ is a Cauchy sequence. Suppose to the contrary that $\left\{x_{n}\right\}$ is not a Cauchy sequence. Then there exists $\varepsilon>0$ for which we can find subsequences $\left\{x_{m(k)}\right\}$ and $\left\{x_{n(k)}\right\}$ where $n(k)$ is the smallest integer such that $n(k)>m(k)>k$ and

$$
d\left(x_{n(k)}, x_{m(k)}, a\right) \geq \varepsilon
$$

for all $k \in \mathbb{N}$. Therefore,

$$
d\left(x_{n(k)-1}, x_{m(k)}, a\right)<\varepsilon .
$$


By using (2.12), (2.13) and (2.14), we have

$$
\begin{aligned}
\varepsilon & \leq d\left(x_{n(k)}, x_{m(k)}, a\right) \\
& \leq d\left(x_{n(k)}, x_{n(k)-1}, a\right)+d\left(x_{n(k)-1}, x_{m(k)}, a\right)+d\left(x_{n(k)}, x_{m(k)}, x_{n(k)-1}\right) \\
& =d\left(x_{n(k)}, x_{n(k)-1}, a\right)+d\left(x_{n(k)-1}, x_{m(k)}, a\right) \\
& <d\left(x_{n(k)}, x_{n(k)-1}, a\right)+\varepsilon .
\end{aligned}
$$

Taking the limit as $k \rightarrow \infty$ in (2.15) and using (2.8), we have

$$
\lim _{k \rightarrow \infty} d\left(x_{n(k)}, x_{m(k)}, a\right)=\lim _{k \rightarrow \infty} d\left(x_{n(k)-1}, x_{m(k)}, a\right)=\varepsilon .
$$

Also, from (2.12), we have

$$
\begin{aligned}
d\left(x_{m(k)}, x_{n(k)-1}, a\right) \leq & d\left(x_{m(k)}, x_{m(k)-1}, a\right)+d\left(x_{m(k)-1}, x_{n(k)-1}, a\right)+d\left(x_{m(k)}, x_{n(k)-1}, x_{m(k)-1}\right) \\
= & d\left(x_{m(k)}, x_{m(k)-1}, a\right)+d\left(x_{m(k)-1}, x_{n(k)-1}, a\right) \\
\leq & d\left(x_{m(k)}, x_{m(k)-1}, a\right) \\
& +d\left(x_{m(k)-1}, x_{n(k)}, a\right)+d\left(x_{n(k)-1}, x_{n(k)}, a\right)+d\left(x_{m(k)-1}, x_{n(k)-1}, x_{n(k)}\right) \\
= & d\left(x_{m(k)}, x_{m(k)-1}, a\right)+d\left(x_{m(k)-1}, x_{n(k)}, a\right)+d\left(x_{n(k)-1}, x_{n(k)}, a\right)
\end{aligned}
$$

and

$$
\begin{aligned}
d\left(x_{m(k)-1}, x_{n(k)}, a\right) & \leq d\left(x_{m(k)-1}, x_{m(k)}, a\right)+d\left(x_{n(k)}, x_{m(k)}, a\right)+d\left(x_{m(k)-1}, x_{n(k)}, x_{m(k)}\right) \\
& =d\left(x_{m(k)-1}, x_{m(k)}, a\right)+d\left(x_{n(k)}, x_{m(k)}, a\right) .
\end{aligned}
$$

Taking the limit as $k \rightarrow \infty$ in (2.17), (2.18) and using (2.8), (2.16), we obtain

$$
\lim _{k \rightarrow \infty} d\left(x_{m(k)-1}, x_{n(k)}, a\right)=\varepsilon
$$

Since $n(k)>m(k)$ and $x_{n(k)-1}, x_{m(k)-1}$ are comparable, by using (2.1), we have

$$
\begin{aligned}
\varepsilon \leq & d\left(x_{n(k)}, x_{m(k)}, a\right) \\
= & d\left(T x_{n(k)-1}, T x_{m(k)-1}, a\right) \\
\leq & \frac{1}{2}\left[d\left(x_{n(k)-1}, T x_{m(k)-1}, a\right)+d\left(x_{m(k)-1}, T x_{n(k)-1}, a\right)\right] \\
& -\psi\left(d\left(x_{n(k)-1}, T x_{m(k)-1}, a\right), d\left(x_{m(k)-1}, T x_{n(k)-1}, a\right)\right) \\
= & \frac{1}{2}\left[d\left(x_{n(k)-1}, x_{m(k)}, a\right)+d\left(x_{m(k)-1}, x_{n(k)}, a\right)\right] \\
& -\psi\left(d\left(x_{n(k)-1}, x_{m(k)}, a\right), d\left(x_{m(k)-1}, x_{n(k)}, a\right)\right) .
\end{aligned}
$$

Taking the limit as $k \rightarrow \infty$ in (2.20) and using (2.16), (2.19) and the continuity of $\psi$, we have

$$
\varepsilon \leq \frac{1}{2}(\varepsilon+\varepsilon)-\psi(\varepsilon, \varepsilon)=\varepsilon-\psi(\varepsilon, \varepsilon) \leq \varepsilon .
$$


This proves that $\psi(\varepsilon, \varepsilon)=0$, that is, $\varepsilon=0$. It is a contradiction. This proves that $\left\{x_{n}\right\}$ is a Cauchy sequence. Since $X$ is complete, there exists $z \in X$ such that $\lim _{n \rightarrow \infty} x_{n}=z$. It follows from the continuity of $T$ that $z=\lim _{n \rightarrow \infty} x_{n+1}=\lim _{n \rightarrow \infty} T x_{n}=T z$. Then $z$ is a fixed point of $T$.

The next result is another one for the existence of the fixed point of a weak $C$-contraction on a 2-metric space. For the preceding one in metric spaces, see [3, Theorem 2.2].

Theorem 2.4 Let $(X, \preceq, d)$ be a complete, partially ordered 2-metric space and $T: X \rightarrow X$ be a weak C-contraction such that:

1. $T$ is non-decreasing.

2. If $\left\{x_{n}\right\}$ is non-decreasing such that $\lim _{n \rightarrow \infty} x_{n}=x$, then $x_{n} \preceq x$ for all $n \in \mathbb{N}$.

3. There exists $x_{0} \in X$ with $x_{0} \preceq T x_{0}$.

Then $T$ has a fixed point.

Proof As in the proof of Theorem 2.3, we have a Cauchy sequence $\left\{x_{n}\right\}$ with $\lim _{n \rightarrow \infty} x_{n}=z$ in $X$. We only have to prove that $T z=z$. Since $\left\{x_{n}\right\}$ is non-decreasing and $\lim _{n \rightarrow \infty} x_{n}=z$, we have $x_{n} \preceq z$ for all $n \in \mathbb{N}$. It follows from (2.1) that

$$
\begin{aligned}
d\left(x_{n+1}, T z, a\right) & =d\left(T x_{n}, T z, a\right) \\
& \leq \frac{1}{2}\left[d\left(x_{n}, T z, a\right)+d\left(z, T x_{n}, a\right)\right]-\psi\left(d\left(x_{n}, T z, a\right), d\left(z, T x_{n}, a\right)\right) \\
& =\frac{1}{2}\left[d\left(x_{n}, T z, a\right)+d\left(z, x_{n+1}, a\right)\right]-\psi\left(d\left(x_{n}, T z, a\right), d\left(z, x_{n+1}, a\right)\right) .
\end{aligned}
$$

Taking the limit as $n \rightarrow \infty$ in (2.21), we have

$$
\begin{aligned}
d(z, T z, a) & \leq \frac{1}{2}[d(z, T z, a)+d(z, z, a)]-\psi(d(z, T z, a), d(z, z, a)) \\
& \leq \frac{1}{2} d(z, T z, a)-\psi(d(z, T z, a), 0) \\
& \leq \frac{1}{2} d(z, T z, a) .
\end{aligned}
$$

It implies that $d(z, T z, a)=0$ for all $a \in X$, that is, $T z=z$.

In what follows, we prove a sufficient condition for the uniqueness of the fixed point in Theorem 2.3 and Theorem 2.4.

\section{Theorem 2.5 Suppose that:}

1. Either hypotheses of Theorem 2.3 or hypotheses of Theorem 2.4 hold.

2. For each $x, y \in X$, there exists $z \in X$ that is comparable to $x$ and $y$.

Then $T$ has a unique fixed point.

Proof As in the proofs of Theorem 2.3 and Theorem 2.4, we see that $T$ has a fixed point.

Now we prove the uniqueness of the fixed point of $T$. Let $x, y$ be two fixed points of $T$. We consider the following two cases. 
Case 1. $x$ is comparable to $y$. Then $T^{n} x$ is comparable to $T^{n} y$ for all $n \in \mathbb{N}$. For all $a \in X$, we have

$$
\begin{aligned}
& d(x, y, a) \\
& \quad=d\left(T^{n} x, T^{n} y, a\right) \\
& \quad \leq \frac{1}{2}\left[d\left(T^{n-1} x, T^{n} y, a\right)+d\left(T^{n-1} y, T^{n} x, a\right)\right]-\psi\left(d\left(T^{n-1} x, T^{n} y, a\right), d\left(T^{n-1} y, T^{n} x, a\right)\right) \\
& \quad=\frac{1}{2}[d(x, y, a)+d(y, x, a)]-\psi(d(x, y, a), d(y, x, a)) \\
& \quad \leq d(x, y, a) .
\end{aligned}
$$

This proves that $\psi(d(x, y, a), d(y, x, a))=0$, that is, $d(x, y, a)=0$ for all $a \in X$. Then $x=y$.

Case 2. $x$ is not comparable to $y$. Then there exists $z \in X$ that is comparable to $x$ and $y$. It implies that $T^{n} z$ is comparable to $T^{n} x=x$ and $T^{n} y=y$. For all $n \in \mathbb{N}$ and $a \in X$, we have

$$
\begin{aligned}
& d\left(x, T^{n} z, a\right) \\
& \quad=d\left(T^{n} x, T^{n} z, a\right) \\
& \quad \leq \frac{1}{2}\left[d\left(T^{n-1} x, T^{n} z, a\right)+d\left(T^{n-1} z, T^{n} x, a\right)\right]-\psi\left(d\left(T^{n-1} x, T^{n} z, a\right), d\left(T^{n-1} z, T^{n} x, a\right)\right) \\
& \quad=\frac{1}{2}\left[d\left(x, T^{n} z, a\right)+d\left(T^{n-1} z, x, a\right)\right]-\psi\left(d\left(x, T^{n} z, a\right), d\left(T^{n-1} z, x, a\right)\right) \\
& \quad \leq \frac{1}{2}\left[d\left(x, T^{n} z, a\right)+d\left(T^{n-1} z, x, a\right)\right]
\end{aligned}
$$

It implies that $d\left(x, T^{n} z, a\right) \leq d\left(x, T^{n-1} z, a\right)$. Then there exists $\lim _{n \rightarrow \infty} d\left(x, T^{n} z, a\right)=l$. Taking the limit as $n \rightarrow \infty$ in (2.22) and noting that $\psi$ is continuous, we have $l \leq \frac{1}{2}(l+$ $l)-\psi(l, l) \leq l$. This proves that $\psi(l, l)=0$. Then $l=0$, that is, $\lim _{n \rightarrow \infty} T^{n} z=x$. Similarly, $\lim _{n \rightarrow \infty} T^{n} z=y$. By Lemma 1.7, we get $x=y$.

Remark 2.6 Note that if $(X, \preceq)$ is totally ordered, then the condition (2) in Theorem 2.5 is always satisfied.

The following result is an analogue of [3, Theorem 3.1].

Theorem 2.7 Let $(X, \preceq, d)$ be a complete, partially ordered 2-metric space and $T: X \rightarrow X$ be a weak $C$-contraction such that:

1. For all $x, y \in X$, if $x \preceq y$ then $T x \succeq T y$.

2. For each $x, y \in X$, there exists $z \in X$ that is comparable to $x$ and $y$.

3. There exists $x_{0} \in X$ with $x_{0} \preceq T x_{0}$ or $x_{0} \succeq T x_{0}$.

Then, for all $a \in X, \inf \{d(x, T x, a): x \in X \backslash\{a\}\}=0$. In particular, $\inf \{d(x, T x, a): x \in X\}=0$.

Proof We consider the following two cases.

Case 1. $x_{0} \preceq T x_{0}$. By the hypothesis (1), consecutive terms of the sequence $\left\{T^{n} x_{0}\right\}$ are comparable. It follows from (2.1) that for all $a \in X$,

$$
\begin{aligned}
& d\left(T^{n+1} x_{0}, T^{n} x_{0}, a\right) \\
& \quad \leq \frac{1}{2}\left[d\left(T^{n} x_{0}, T^{n} x_{0}, a\right)+d\left(T^{n-1} x_{0}, T^{n+1} x_{0}, a\right)\right]
\end{aligned}
$$




$$
\begin{aligned}
& -\psi\left(d\left(T^{n} x_{0}, T^{n} x_{0}, a\right), d\left(T^{n-1} x_{0}, T^{n+1} x_{0}, a\right)\right) \\
= & \frac{1}{2} d\left(T^{n-1} x_{0}, T^{n+1} x_{0}, a\right)-\psi\left(0, d\left(T^{n-1} x_{0}, T^{n+1} x_{0}, a\right)\right) \\
\leq & \frac{1}{2} d\left(T^{n-1} x_{0}, T^{n+1} x_{0}, a\right) \\
\leq & \frac{1}{2}\left[d\left(T^{n-1} x_{0}, T^{n} x_{0}, a\right)+d\left(T^{n} x_{0}, T^{n+1} x_{0}, a\right)+d\left(T^{n-1} x_{0}, T^{n} x_{0}, T^{n+1} x_{0}\right)\right] .
\end{aligned}
$$

As in the proof of (2.12) of Theorem 2.3, we have $d\left(x_{i}, x_{j}, x_{k}\right)=0$ for all $i, j, k \in \mathbb{N}$. Then (2.23) implies

$$
d\left(T^{n+1} x_{0}, T^{n} x_{0}, a\right) \leq \frac{1}{2}\left[d\left(T^{n-1} x_{0}, T^{n} x_{0}, a\right)+d\left(T^{n} x_{0}, T^{n+1} x_{0}, a\right)\right] .
$$

That is, $d\left(T^{n+1} x_{0}, T^{n} x_{0}, a\right) \leq d\left(T^{n} x_{0}, T^{n-1} x_{0}, a\right)$. Then there exists $\lim _{n \rightarrow \infty} d\left(T^{n+1} x_{0}\right.$, $\left.T^{n} x_{0}, a\right)=r$. As in the proof of Theorem 2.3, we get $r=0$. Then $\lim _{n \rightarrow \infty} d\left(T^{n+1} x_{0}\right.$, $\left.T^{n} x_{0}, a\right)=0$. That is, $\inf \{d(x, T x, a): x \in X\}=0$.

Case 2. $x_{0} \succ T x_{0}$. The same as in Case 1 .

For each $a \in X$, if $d_{a}(x, y)=d(x, y, a)$ for all $x, y \in X$ is a metric on $X$, then the formula (2.1) becomes (1.1). Also, the above proofs may be similar to the method used in [2] and [3]. The following example guarantees that this fact is not true in general.

Example 2.8 There exists a 2-metric space $(X, d)$ such that for each $a \in X$, the formula $d_{a}(x, y)=d(x, y, a)$ for all $x, y \in X$ is not a metric on $X$.

Proof Let $X=[0,+\infty)$ and

$$
d(x, y, z)= \begin{cases}x y+y z+z x & \text { if } x \neq y \neq z \\ 0 & \text { otherwise }\end{cases}
$$

Then $(X, d)$ is a 2 -metric space. For each $a \in X$, we have

$$
d_{a}(x, y)=d(x, y, a)= \begin{cases}x y+y a+a x & \text { if } x \neq y \neq a, \\ 0 & \text { otherwise. }\end{cases}
$$

If $a=0$, then we have

$$
d_{0}(1,6)=6>d_{0}\left(1, \frac{1}{6}\right)+d_{0}\left(\frac{1}{6}, 6\right)=\frac{1}{6}+1=\frac{7}{6} .
$$

If $a \neq 0$, then we have

$$
d_{a}(2 a, 3 a)=11 a^{2}>d_{a}(2 a, 0)+d_{a}(0,3 a)=2 a^{2}+3 a^{2}=5 a^{2} .
$$

This proves that $d_{a}$ is not a metric on $X$ for all $a \in X$.

The following example shows that hypotheses in Theorem 2.3 and Theorem 2.4 do not guarantee the uniqueness of the fixed point. 
Example 2.9 Let $X=\{(1,0),(0,1),(2,-2)\} \subset \mathbb{R}^{2}$ with the order

$$
(x, y) \preceq(z, t) \text { if and only if } \quad x \leq z \text { and } y \leq t .
$$

Define a 2-metric $d$ on $X$ as follows:

$$
d(x, y, z)= \begin{cases}\sqrt{2} & \text { if } x \neq y \neq z \\ 0 & \text { otherwise }\end{cases}
$$

Then $(X, \preceq, d)$ is a partially ordered, complete 2 -metric space whose different elements are not comparable. The identity map $T(x, y)=(x, y)$ for all $(x, y) \in X$ is continuous, nondecreasing, and contraction conditions in Theorem 2.3 and Theorem 2.4 are satisfied. Moreover, $(1,0) \preceq T(1,0)$ and $T$ has more than one fixed point.

The following example is an illustration of Theorem 2.4 and Theorem 2.7.

Example 2.10 Let $X=\{a, b, c\}$ with the order $x \preceq y$ if and only if $x=y$ for all $x, y \in X$. Let $d$ be a 2 -metric on $X$ defined by the symmetry of all three variables and

$$
d(x, y, z)= \begin{cases}1 & \text { if } x \neq y \neq z \\ 0 & \text { otherwise }\end{cases}
$$

Let $T: X \rightarrow X$ be defined by $T a=b, T b=a, T c=c$. It is easy to see that Theorem 2.4 and Theorem 2.7 are applicable to $T$ and $c$ is a unique fixed point of $T$. Moreover, the condition (2) in Theorem 2.5 does not hold, then it is not a necessary condition of the uniqueness of the fixed point.

Note that, in [3, Theorem 3.1], if $X$ is a compact metric space and $T$ is continuous, then $T$ has a unique fixed point. The following example shows that, in Theorem 2.7, if $X$ is a compact 2-metric space and $T$ is continuous, then $T$ may not have a unique fixed point.

Example 2.11 Let $(X, d)$ be a 2-metric space as in Example 2.10. Let $T: X \rightarrow X$ be defined by

$$
T a=a, \quad T b=b, \quad T c=c .
$$

We see that all assumptions in Theorem 2.7 are satisfied but $T$ has more than one fixed point.

Finally, Example 2.12 and Example 2.13 show that the above results can be used to prove the existence of a fixed point when standard arguments in metric spaces in [2] and [3] fail, even for trivial maps.

Example 2.12 Let $X$ be the 2-metric space $(R, \sigma)$ on [4, p.145] with the usual order and $T x=0$ for all $x \in X$. Then we have:

1. $X$ is a complete, totally ordered 2-metric space.

2. $X$ is not metrizable.

3. $T$ is a $C$-weak contraction on the 2 -metric space $X$. 
Proof (1) and (2) See [4, p.145].

(3) By choosing $\psi(a, b)=\frac{a+b}{2}$ for all $a, b \in[0,+\infty)$, then the condition (2.1) holds. This proves that $T$ is a $C$-weak contraction on the 2-metric space $X$.

Example 2.13 Let $X=\{0,1,2, \ldots, n, \ldots\}$ with the usual order,

$$
d(x, y, z)= \begin{cases}1 & \text { if } x \neq y \neq z \text { and there exists } n \geq 1 \text { with }\{n, n+1\} \subset\{x, y, z\} \\ 0 & \text { otherwise }\end{cases}
$$

and $T x=0$ for all $x \in X$. Then we have:

1. $(X, d)$ is a complete, totally ordered 2-metric space.

2. $(X, d)$ is not completely metrizable, that is, there does not exist any metric $\rho$ on $X$ such that the metric topology and the completeness on $(X, \rho)$ are coincident with the 2 -metric topology and the completeness on $(X, d)$, respectively.

3. $T$ is a $C$-weak contraction on the 2 -metric space $(X, d)$.

Proof (1) It is easy to see that $(X, d)$ is a partially ordered 2-metric space.

Let $\left\{x_{n}\right\}$ be a Cauchy sequence in $(X, d)$. We have $\lim _{n, m \rightarrow \infty} d\left(x_{n}, x_{m}, a\right)=0$ for all $a \in X$. Then, for each $a \in X$, there exists $n_{0}(a)$ such that $d\left(x_{n}, x_{m}, a\right)=0$ for all $n, m \geq n_{0}(a)$. We consider the following three cases.

Case 1. For all $n, m \geq n_{0}(a), x_{n}=x_{m}$. This proves that $\left\{x_{n}\right\}$ is convergent.

Case 2. For all $n \geq n_{0}(a), x_{n}=a$. It is a contradiction because $a$ is an arbitrary point of $X$.

Case 3. For all $n, m \geq n_{0}(a)$ and all $k \geq 1, x_{n} \neq x_{m} \neq a$ and $\{k, k+1\} \not \subset\left\{x_{n}, x_{m}, a\right\}$. Then $d\left(x_{n}, 0, a\right)=0$ for all $n \geq n_{0}(a)$. This proves that $\left\{x_{n}\right\}$ is convergent.

By the above three cases, the Cauchy sequence $\left\{x_{n}\right\}$ is convergent in $(X, d)$. This proves that $(X, d)$ is complete.

(2) Since $\lim _{n \rightarrow \infty} d(n, 0, a)=0$, we have $\{n\}$ is a convergent sequence in $(X, d)$. On the other hand, $\lim _{n \rightarrow \infty} d(n, n+1, a)=1$, then $\{n\}$ is not a Cauchy sequence in $(X, d)$. This proves that $(X, d)$ is not completely metrizable.

(3) By choosing $\psi(a, b)=\frac{a+b}{2}$, the condition (2.1) holds. This proves that $T$ is a $C$-weak contraction on the 2-metric space $(X, d)$.

Competing interests

The authors declare that they have no competing interests.

Authors' contributions

All authors contributed equally and significantly in writing this paper. All authors read and approved the final manuscript.

\section{Author details}

'Department of Mathematics, Dong Thap University, Dong Thap, Dong Thap, Vietnam. ${ }^{2}$ Journal of Science, Dong Thap University, Cao Lanh, Dong Thap, Vietnam.

\section{Acknowledgements}

The authors would like to thank the referees for their valuable comments.

Received: 10 February 2013 Accepted: 30 May 2013 Published: 21 June 2013

\section{References}

1. Chatterjea, SK: Fixed point theorems. C. R. Acad. Bulgare Sci. 25, 727-730 (1972)

2. Choudhury, BS: Unique fixed point theorem for weakly C-contractive mappings. Kathmandu Univ. J. Sci. Eng. Technol. 5, 6-13 (2009) 
3. Harjani, J, López, B, Sadarangani, K: Fixed point theorems for weakly C-contractive mappings in ordered metric spaces. Comput. Math. Appl. 61, 790-796 (2011)

4. Gähler, VS: 2-metrische Räume und ihre topologische struktur. Math. Nachr. 26, 115-118 (1963/64)

5. Dhage, BC: A study of some fixed point theorems. PhD thesis, Marathwada, Aurangabad, India (1984)

6. Mustafa, Z, Sims, B: Some remarks concerning D-metric spaces. In: Proceedings of the International Conferences on Fixed Point Theory and Applications, Valencia, Spain, pp. 189-198 (2003)

7. Mustafa, Z, Sims, B: A new approach to generalized metric spaces. J. Nonlinear Convex Anal. 7(2), $289-297$ (2006)

8. Jleli, M, Samet, B: Remarks on G-metric spaces and fixed point theorems. Fixed Point Theory Appl. 2012,201 (2012)

9. Samet, B, Vetro, C, Vetro, F: Remarks on G-metric spaces. Int. J. Anal. 2013, 1-6 (2013)

10. Huang, LG, Zhang, X: Cone metric spaces and fixed point theorems of contractive mappings. J. Math. Anal. Appl. 332 1468-1476 (2007)

11. Du, WS: A note on cone metric fixed point theory and its equivalence. Nonlinear Anal. 72, 2259-2261 (2010)

12. Feng, Y, Mao, W: The equivalence of cone metric spaces and metric spaces. Fixed Point Theory 11(2), 259-264 (2010)

13. Kadelburg, Z, Radenović, S, Rakočević, V: A note on the equivalence of some metric and cone metric fixed point results. Appl. Math. Lett. 24(3), 370-374 (2011)

14. Khani, M, Pourmahdian, M: On the metrizability of cone metric spaces. Topol. Appl. 158(2), 190-193 (2011)

15. Azam, A, Fisher, B, Khan, M: Common fixed point theorems in complex valued metric spaces. Numer. Funct. Anal. Optim. 32(3), 243-253 (2011)

16. Sastry, KPR, Naidu, GA, Bekeshie, T: Metrizability of complex valued metric spaces and some remarks on fixed point theorems in complex valued metric spaces. Int. J. Pure Appl. Math. 3(7), 2686-2690 (2012)

17. Aliouche, A, Simpson, C: Fixed points and lines in 2-metric spaces. Adv. Math. 229, 668-690 (2012)

18. Deshpande, B, Chouhan, S: Common fixed point theorems for hybrid pairs of mappings with some weaker conditions in 2-metric spaces. Fasc. Math. 46, 37-55 (2011)

19. Freese, RW, Cho, YJ, Kim, SS: Strictly 2-convex linear 2-normed spaces. J. Korean Math. Soc. 29(2), 391-400 (1992)

20. Gähler, VS: Lineare 2-normierte Räume. Math. Nachr. 28, 1-43 (1965)

21. Gähler, VS: Über die uniformisierbarkeit 2-metrischer Räume. Math. Nachr. 28, 235-244 (1965)

22. Iseki, K: Fixed point theorems in 2-metric spaces. Math. Semin. Notes 3, 133-136 (1975)

23. Iseki, K: Mathematics on 2-normed spaces. Bull. Korean Math. Soc. 13(2), 127-135 (1976)

24. Lahiri, BK, Das, P, Dey, LK: Cantor's theorem in 2-metric spaces and its applications to fixed point problems. Taiwan. J. Math. 15, 337-352 (2011)

25. Lai, SN, Singh, AK: An analogue of Banach's contraction principle of 2-metric spaces. Bull. Aust. Math. Soc. 18, 137-143 (1978)

26. Vats, RK, Kumar, S, Sihag, V: Fixed point theorems in complete G-metric space. Fasc. Math. 47, 127-139 (2011)

27. Naidu, SVR, Prasad, JR: Fixed point theorems in 2-metric spaces. Indian J. Pure Appl. Math. 17(8), 974-993 (1986)

doi:10.1186/1687-1812-2013-161

Cite this article as: Dung and Le Hang: Fixed point theorems for weak C-contractions in partially ordered 2-metric spaces. Fixed Point Theory and Applications 2013 2013:161.

\section{Submit your manuscript to a SpringerOpen ${ }^{\circ}$ journal and benefit from:}

- Convenient online submission

Rigorous peer review

- Immediate publication on acceptance

Open access: articles freely available online

- High visibility within the field

- Retaining the copyright to your article 